\title{
A Novel NDT Method for Coercive Force of Grain-Oriented Electrical Steel Applied in Cigarette Machines
}

\author{
Hao Wang, ${ }^{1}$ Jianbo Zhan, ${ }^{1}$ Zhenhua Yu, ${ }^{1}$ Yao Yu, ${ }^{1}$ Liang Cheng, ${ }^{1}$ Baoshan Yue, \\ Yafeng Ji, ${ }^{2}$ Shuzong Chen, ${ }^{3}$ Li Wang, ${ }^{3}$ and Chen Chen ${ }^{4}$ \\ ${ }^{1}$ Research and Development Center, China Tobacco Yunnan Industrial Co., Ltd., Kunming 650231, China \\ ${ }^{2}$ Heavy Industry Engineering Center of China Ministry of Education, Taiyuan University of Science and Technology, \\ Taiyuan 030024, China \\ ${ }^{3}$ State Key Laboratory of Rolling and Automation, Northeastern University, Shenyang 110819, China \\ ${ }^{4}$ School of Mechanical Engineering, Shenyang University of Technology, Shenyang 110870, China
}

Correspondence should be addressed to Hao Wang; neuwanghao@gmail.com

Received 19 June 2016; Accepted 10 August 2016

Academic Editor: Miaoquan Li

Copyright (C) 2016 Hao Wang et al. This is an open access article distributed under the Creative Commons Attribution License, which permits unrestricted use, distribution, and reproduction in any medium, provided the original work is properly cited.

Coercive force of grain-oriented electrical steel applied in cigarette machines is tested by a novel NDT method in which Barkhausen noise was applied. Linear relationship between coercive force and Barkhausen noise of conventional and high-permeability electrical steel was built and the precision of the model was verified. Experimental results show that the coercive force is linearly related to Barkhausen noise. The variation of coercive force with magnetic induction intensity increase was also interpreted in view of magnetic domain changing process, and the correlation formula derivation of MBN and coercive force domain wall was illustrated as well.

\section{Introduction}

Grain-oriented electrical steels are widely used in industrial fields such as electronics and electric power [1]. The coercive force value of grain-oriented electrical steels is one of the main magnetic properties. In the present measuring method of electrical steel, the method of measuring the magnetic properties is mainly based on the standard of single sheet tester (SST), and the standard sample of the finished product is processed by the experimental apparatus [2-5].

The basic performance requirement of soft magnetic material is that it can quickly respond to the external magnetic field, which requires that the material has a low coercive force $[6,7]$. The lower the coercive force is, the more sensitive the response is in the low magnetic field [8]. The coercive force is related to the external magnetic field strength, which is a point on the magnetic hysteresis loop, which reflects the hysteresis characteristics of the material [9-11]. Coercive force is one main magnetic property of grainoriented electrical steel, and the performance of the coercive force influences other magnetic parameters, further affecting the electromagnetic properties of the electrical products [12]. For example, coercive force affects the release parameters of electromagnetic relay. If the coercive force of electrical steel is higher, there is more remanent magnetization, and the permeability is lower, resulting in the decrease of product release voltage. Such decrease will lead to failure to cut off the circuit relay, causing failure of the controlled system. The coercive force measurement can be carried out in a closed magnetic circuit; however, it is difficult to get accurate data as during the measurement it must overcome the error caused by the magnetic yokes [13-15].

The coercive force of the samples and other magnetic materials is measured in the magnetic circuit, which has been widely used in industry [16-18]. The wide application fields include the coercive force test of soft magnetic material components applied in measuring instrument, electric relay, and solenoid valve, also including the performance check of bearing, metal cutting tools, heat treatment, welding, grinding, and other industrial processes [19-21]. It could also be 
TABLE 1: Chemical composition of HGO and CGO electrical steel (wt\%).

\begin{tabular}{ccccccccc}
\hline & $\mathrm{Si}$ & $\mathrm{C}$ & $\mathrm{Mn}$ & $\mathrm{S}$ & $\mathrm{Cu}$ & $\mathrm{Al}$ & $\mathrm{N}$ & $\mathrm{Fe}$ \\
\hline HGO & 3.12 & 0.05 & 0.14 & 0.01 & 0.09 & 0.03 & 0.01 & Bal. \\
CGO & 3.05 & 0.03 & 0.15 & 0.01 & 0.04 & 0.03 & 0.02 & Bal. \\
\hline
\end{tabular}

applied in the quality inspection of steel products and in the hardness control of the bearing and tools.

In the different parts of cigarette machines, including rod forming machine, tobacco feeding machine, cutting machine, and manipulator, they all have detecting devices made of electrical steel, which requires testing of coercive force. In this paper, we investigated the coercive force of HGO and CGO electrical steel and provoked a novel NDT method for coercive force which has advantages of high accuracy and quick response, which could be used in electrical steel for cigarette machines.

\section{Experimental}

The grain-oriented electrical steel samples were provided by Cogent Power Co., Ltd. Tested samples were composed of conventional and high-permeability electrical steel, and the average grain sizes of the samples are approximately $4 \mathrm{~mm}$ and $9 \mathrm{~mm}$, respectively. Two types of electrical steel were named as CGO and HGO, respectively, and their chemical composition is shown in Table 1.

The samples are all standard Epstein samples, sample size of $350 \mathrm{~mm} \times 30 \mathrm{~mm} \times 0.3 \mathrm{~mm}$. Initial measured magnetic properties (coercive force, Barkhausen noise, power loss, and permeability) of CGO and HGO (1.0 T) are shown in Table 2.

Epstein frame was applied in the magnetic measurements, and to control the flux density a feedback control system was used, inducing secondary sinusoidal voltage waveform for repeatable magnetic properties results. The computer was away from the testing system to avoid causing interference with the experiment. Every testing strip was magnetized along the rolling direction in flux density from $0.1 \mathrm{~T}$ to $1.5 \mathrm{~T}$ with sinusoidal wave, and the magnetizing frequency is $50 \mathrm{~Hz}$. Coercive force and Barkhausen noise measurements were made three times to get the average value. The sample was drawn from the frame and demagnetized before measurement.

In the present work, a measuring system with high accuracy was developed for the magnetization and automatic measurement of coercive force and Barkhausen noise of electrical steel at different magnetic induction intensities. Figure 1 shows the systems' schematic diagram [22]. Two electrical steel vertical yokes were applied, between which a standard testing Epstein strip could be placed. From the DAQ card the magnetizing voltage was produced by the LabVIEW program. The voltage differences between the shunt resistor and the secondary voltage were collected to calculated the magnetic field intensity and induction intensity, respectively. The system could accurately accomplish low-field measurements as the data acquisition card resolution could sense signals as weak as $10^{-6} \mathrm{~V}$.

\section{Results and Discussion}

3.1. Linear Relationship of Coercive Force and Barkhausen Noise. Coercive force increases with the magnetic induction intensity of HGO and CGO electrical steel, which can be seen in Figure 2.

Coercive force shows linear relationship with the magnetic induction intensity, which presents similar changing trend to that of Barkhausen noise in our previous work [22]. Therefore, we calculated the relationship of coercive force and Barkhausen noise. As shown in Figure 3, Barkhausen noise shows linear relationship with coercive force in both HGO and CGO electrical steel. We made linear fitting of the relationship of HGO electrical steel, and the fitting equation is as follows:

$$
F=462.30 U+81.08
$$

The fitting degree is 0.991 , which is high fitting degree.

We also made linear fitting of the relationship of CGO electrical steel, and the fitting equation is as follows:

$$
F=656.61 U+55.54 \text {. }
$$

The fitting degree is 0.994 , which is high fitting degree.

3.2. Energy and Domain Wall Analysis. When a ferromagnetic material is affected by an external magnetic field, there is irreversible motion of the magnetic domain walls. Through the inclusions or defects of magnetization pinning, hindered motion, enough energy will accumulate in the external magnetic field to induce sudden movement of domain walls before they are pinned again. In every time there was suddenly nail bar or suddenly from the pinning in the test instrument of detecting coil produces an electrical pulse, namely, Barkhausen noise.

In view of magnetic domain and domain wall energy theory and previous study, new secondary magnetic domains will take shape along the rolling direction of the grainoriented electrical steel sheets during the magnetizing process. For grain-oriented electrical steel sheets, increase of equilibrium distance between domain walls induced coercive force to rise. As the magnetic elastic energy caused by magnetization increases, transverse secondary magnetic domains form, and spiky secondary magnetic domains form in order to limit the increase of magnetostatic energy generated by surface free magnetic poles. However, in grainoriented electrical steels such secondary magnetic domains formed in primary magnetic domains are not stable, which quickly absorb former primary magnetic domains and grow, causing formation of new primary magnetic domains. If there is further treatment of electrical steel, such as ball scribing, through the appearance and development of free magnetic poles and secondary magnetic domains due to the stress primary magnetic domain spacing of grain-oriented electrical steel becomes smaller, reducing coercive force of electrical steel.

3.3. A Novel NDT Method for Measuring Coercive Force. Due to the high linear fitting degree, we proposed a novel NDT 
TABLE 2: Initial magnetic properties of HGO and CGO electrical steel at 1.0 T.

\begin{tabular}{lcccc}
\hline & Iron loss $/(\mathrm{W} / \mathrm{kg})$ & Coercive force $/(\mathrm{A} / \mathrm{m})$ & Relative permeability & Barkhausen noise $/(\mathrm{mV})$ \\
\hline HGO & 0.668 & 287.6 & 2473.7 & 0.447 \\
CGO & 0.711 & 282.9 & 799.4 & 0.391 \\
\hline
\end{tabular}

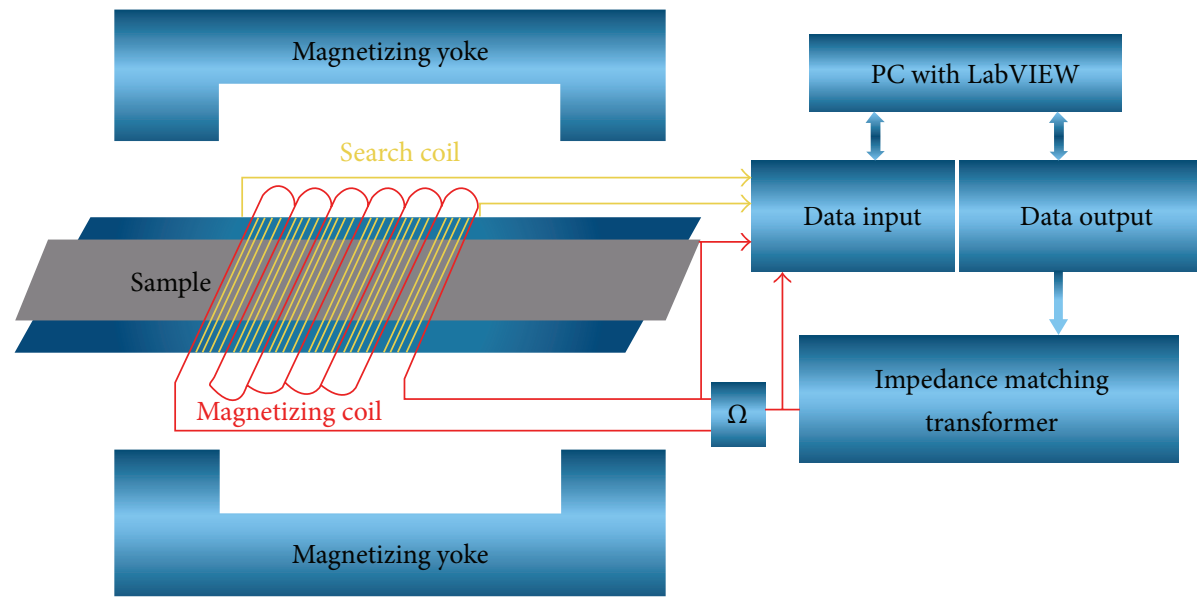

FIGURE 1: Schematic diagram of magnetic measurement system [22].

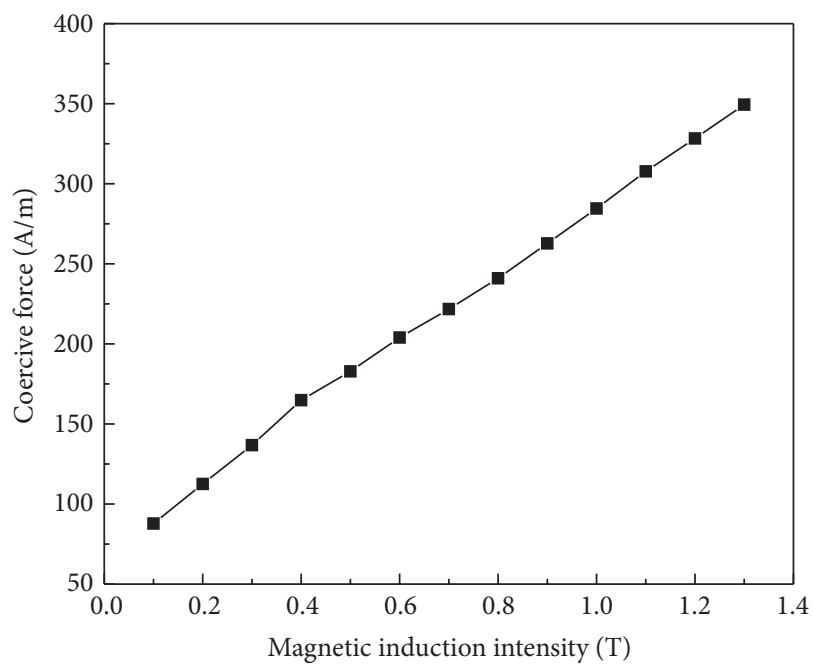

(a)

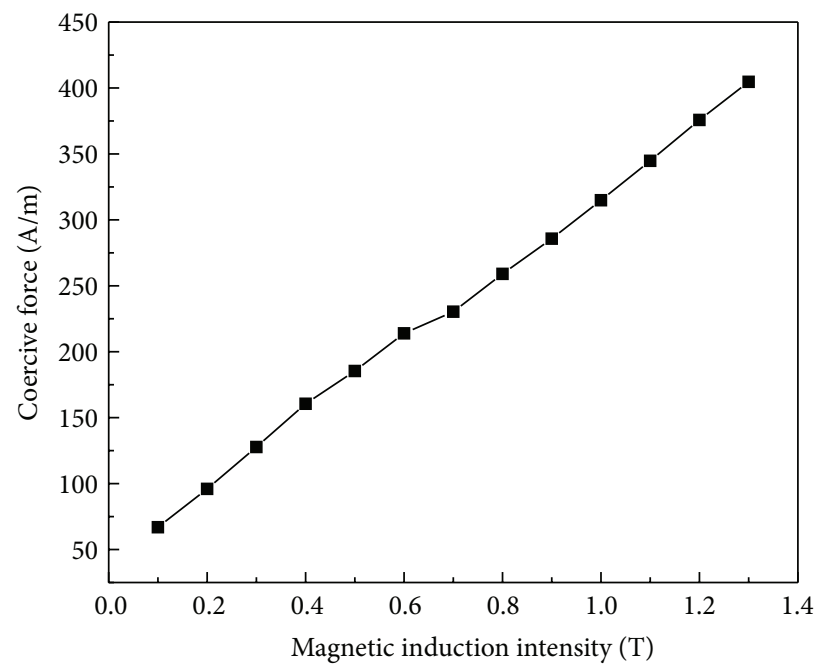

(b)

FIGURE 2: Relationship of coercive force and magnetic induction intensity of (a) HGO and (b) CGO electrical steel.

method for coercive force detection of grain-oriented electrical steel applied in cigarette machines. The NDT method applies linear relationship of Barkhausen noise and coercive force. As Barkhausen noise is widely applied in the NDT technology to detect microstructure and other defects of various materials, it could also be applied as NDT method for testing coercive force of HGO and CGO electrical steel. The comparison of NDT measured and traditional SST measured coercive force is shown in Tables 3 and 4, respectively.

Under a certain magnetic induction intensity by Barkhausen measurement instrument the Barkhausen signal values (voltage RMS) could be detected as a variable input, through the model calculated coercive force values as output data.

By using this method the coercive force value has a corresponding magnetization voltage value generated. At the same step voltage, the coercive force of the electrical steel varies linearly with the changes in the magnetic field strength. If the magnetization force obtained a value, electrical steel pole molecules will rotate, containing coercive force change in a rotational manner that appeared in the process of Barkhausen noise signal. Through the detection system design and the 


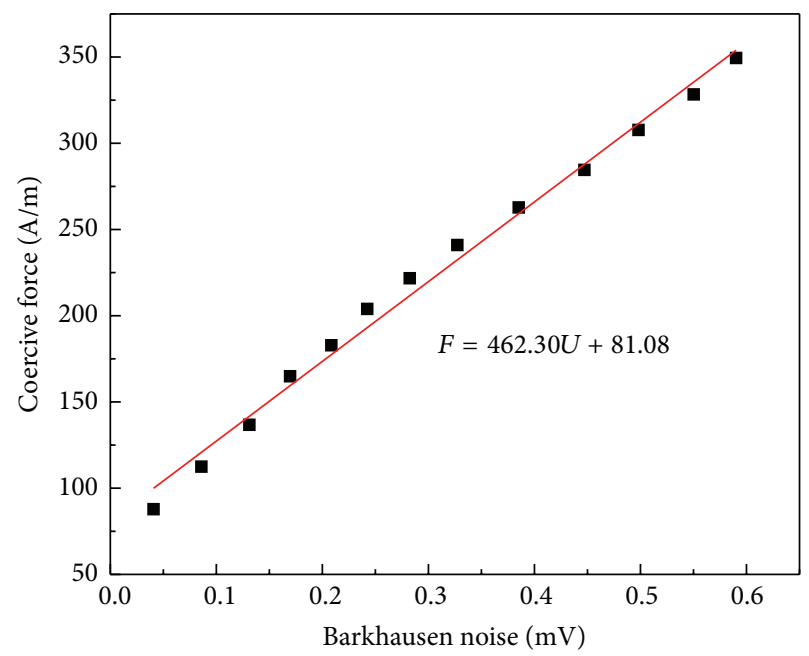

(a)

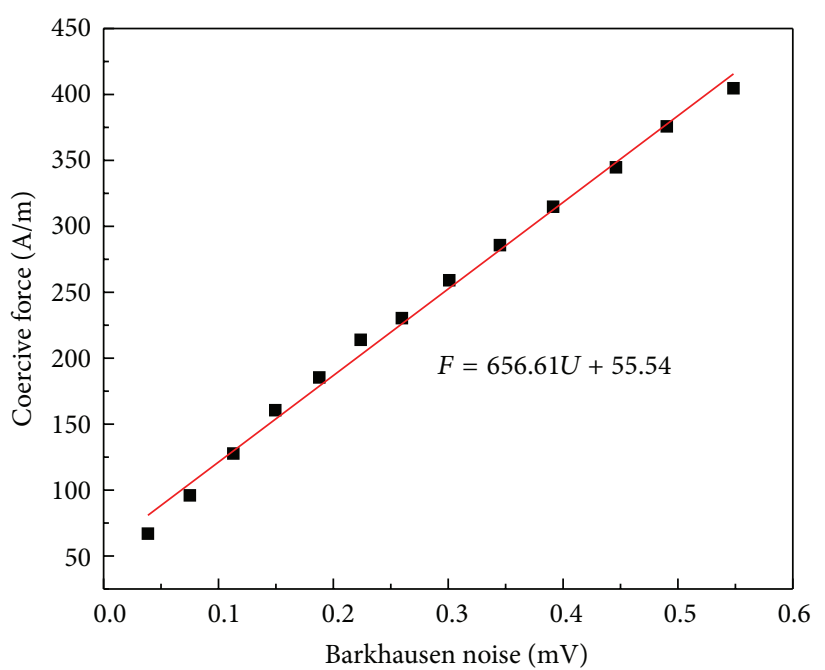

(b)

FIGURE 3: Linear fitting of coercive force and Barkhausen noise of (a) HGO and (b) CGO electrical steel.

TABLE 3: Comparison of SST measured and calculated coercive force of HGO electrical steel.

\begin{tabular}{lcccccc}
\hline Magnetic induction intensity $(\mathrm{T})$ & 0.3 & 0.5 & 0.7 & 0.9 & 1.1 & 1.3 \\
Barkhausen noise $(\mathrm{mV})$ & 0.131 & 0.209 & 0.282 & 0.385 & 0.498 & 0.590 \\
NDT measured coercive force $(\mathrm{A} / \mathrm{m})$ & 141.71 & 177.47 & 211.63 & 259.15 & 311.40 & 353.94 \\
SST measured coercive force $(\mathrm{A} / \mathrm{m})$ & 136.76 & 182.84 & 221.74 & 262.75 & 307.74 \\
\hline
\end{tabular}

TABLE 4: Comparison of SST measured and calculated coercive force of CGO electrical steel.

\begin{tabular}{|c|c|c|c|c|c|c|}
\hline Magnetic induction intensity $(\mathrm{T})$ & 0.3 & 0.5 & 0.7 & 0.9 & 1.1 & 1.3 \\
\hline Barkhausen noise $(\mathrm{mV})$ & 0.113 & 0.188 & 0.260 & 0.345 & 0.446 & 0.548 \\
\hline NDT measured coercive force $(\mathrm{A} / \mathrm{m})$ & 129.68 & 178.83 & 226.04 & 282.09 & 348.44 & 415.61 \\
\hline SST measured coercive force $(\mathrm{A} / \mathrm{m})$ & 127.72 & 185.37 & 230.36 & 285.74 & 344.75 & 404.69 \\
\hline
\end{tabular}

data in the data file the corresponding linear processing can realize online detection of the coercive force of electrical steel by the Barkhausen noise voltage RMS detection.

The results show that the method of soft measurement is close to the standard of Epstein specimen in the experiment, which can meet the accuracy requirements.

The novel NDT method could be applied for the online detection of the coercive force of electrical steel and be easy in carrying out the standard processing of the measuring object. The detection method has the advantages of high sensitivity and reliability and good repeatability. The detection equipment is of light weight, small size, and fast detection speed, being especially suitable for online detection in the field.

\section{Conclusions}

(1) Coercive force of HGO and CGO electrical steel increases with the rise of magnetic induction intensity.

(2) Linear fitting models of coercive force and Barkhausen noise were built; the high fitting degree proves that there exists linear relationship of coercive force and Barkhausen noise. The linear relationship is due to similar changing process caused by magnetic domain and domain wall energy during the magnetization.

(3) On the basis of linear relationship, a novel NDT method for coercive force of grain-oriented electrical steel applied in cigarette machines was proposed. The method is mainly used for the online detection of the coercive force of electrical steel. The detection method possesses the advantages of high sensitivity and reliability and good repeatability. The detection equipment is of light weight, small size, and fast detection speed, being especially suitable for online detection in the field.

\section{Competing Interests}

The work did not lead to any conflict of interests regarding the publication of this manuscript. 


\section{Acknowledgments}

The financial support of National Natural Science Foundation of China (Grant no. 51404159), Science and Technology Project of Hebei Province (Grant no. 152177180), and Science and Technology Project of Qinhuangdao City (Grant no. 201502A037) is greatly acknowledged. Authors thank Wolfson Centre for Magnetics, Cardiff University, for part of experimental equipment support to this work.

\section{References}

[1] A. J. Moses, "Energy efficient electrical steels: magnetic performance prediction and optimization," Scripta Materialia, vol. 67, no. 6, pp. 560-565, 2012.

[2] H. Wang, C.-S. Li, and T. Zhu, "Hard magnetization direction and its relation with magnetic permeability of highly grainoriented electrical steel," International Journal of Minerals, Metallurgy and Materials, vol. 21, no. 11, pp. 1077-1082, 2014.

[3] H. Wang, C.-S. Li, R.-B. Mei, and G. Huo, "Effect of ball scribing on magnetic shielding efficiency of grain-oriented silicon steel," Journal of Iron and Steel Research, International, vol. 21, no. 7, pp. 679-684, 2014.

[4] F. J. G. Landgraf, J. R. F. Da Silveira, and D. Rodrigues-Jr, "Determining the effect of grain size and maximum induction upon coercive field of electrical steels," Journal of Magnetism and Magnetic Materials, vol. 323, no. 18-19, pp. 2335-2339, 2011.

[5] V. N. Kostin and O. N. Vasilenko, "On new possibilities for making local measurements of the coercive force of ferromagnetic objects," Russian Journal of Nondestructive Testing, vol. 48, no. 7, pp. 401-410, 2012.

[6] A. A. Chulkina and A. I. Ul'Yanov, "Effect of the magnetic properties of cementite on the coercive force of high-carbon steels after quenching and tempering," The Physics of Metals and Metallography, vol. 108, no. 6, pp. 548-555, 2009.

[7] V. Sudharsanam, V. Senthilkumar, N. Raju, and R. Vetriselvan, "Evaluation of post weld heat treatment quality of modified 9Cr-1Mo (P91) steel weld by magnetic coercive force measurements," Archives of Civil and Mechanical Engineering, vol. 15, no. 4, pp. 847-853, 2015.

[8] J. L. Li, L. J. Zhang, Y. X. Wang et al., "Effect and mechanism of ion bombardment on coercive force of $\mathrm{NdFeB}$ magnet," Materials Letters, vol. 98, pp. 102-104, 2013.

[9] H. Sepehri-Amin, L. H. Liu, T. Ohkubo et al., "Microstructure and temperature dependent of coercivity of hot-deformed Nd$\mathrm{Fe}-\mathrm{B}$ magnets diffusion processed with $\mathrm{Pr}-\mathrm{Cu}$ alloy," Acta Materialia, vol. 99, no. 10, pp. 297-306, 2015.

[10] W.-L. Zuo, M. Zhang, E. Niu et al., "The coercivity mechanism of Pr-Fe-B nanoflakes prepared by surfactant-assisted ball milling," Journal of Magnetism and Magnetic Materials, vol. 390, no. 9, pp. 15-19, 2015.

[11] S. H. Liu, S. N. Hsiao, S. K. Chen, and H. Y. Lee, "Substantial reduction in coercivity of perpendicular $\mathrm{CoPt} / \mathrm{FePt}$ graded films with near-atomic flatness on glass substrates," Journal of Alloys and Compounds, vol. 631, no. 5, pp. 15-20, 2015.

[12] B. S. Schröder, J. B. Walters, and K. A. Evans, "A Cacciopolitype inequality to prove coercivity of a bilinear form associated with spatial hysteresis internal damping for an Euler-Bernoulli beam," Journal of Mathematical Analysis and Applications, vol. 425, no. 1, pp. 520-535, 2015.
[13] T. T. Sasaki, T. Ohkubo, Y. Une, H. Kubo, M. Sagawa, and K. Hono, "Effect of carbon on the coercivity and microstructure in fine-grained Nd-Fe-B sintered magnet," Acta Materialia, vol. 84, pp. 506-514, 2015.

[14] C. Bran, A. P. Espejo, E. M. Palmero, J. Escrig, and M. Vázquez, "Angular dependence of coercivity with temperature in Co-based nanowires," Journal of Magnetism and Magnetic Materials, vol. 396, no. 12, pp. 327-332, 2015.

[15] J. Liu, H. Sepehri-Amin, T. Ohkubo et al., "Grain size dependence of coercivity of hot-deformed $\mathrm{Nd}-\mathrm{Fe}-\mathrm{B}$ anisotropic magnets," Acta Materialia, vol. 82, no. 1, pp. 336-343, 2015.

[16] H. Sepehri-Amin, T. Ohkubo, M. Gruber, T. Schrefl, and K. Hono, "Micromagnetic simulations on the grain size dependence of coercivity in anisotropic Nd-Fe-B sintered magnets," Scripta Materialia, vol. 89, pp. 29-32, 2014.

[17] M. Matsuura, K. Isogai, K. Shinaji, N. Tezuka, and S. Sugimoto, "Microstructure and coercivity of nitrided Mn-Sn-based alloys," Journal of Alloys and Compounds, vol. 605, no. 8, pp. 208-212, 2014.

[18] L. Kumar, P. Kumar, and M. Kar, "Non-linear behavior of coercivity to the maximum applied magnetic field in La substituted nanocrystalline cobalt ferrite," Physica B: Condensed Matter, vol. 448, no. 9, pp. 38-42, 2014.

[19] S. Mirzaee, S. F. Shayesteh, S. Mahdavifar, and S. H. Hekmatara, "Synthesis, characterization and Monte Carlo simulation of $\mathrm{CoFe}_{2} \mathrm{O}_{4} /$ Polyvinylpyrrolidone nanocomposites: the coercivity investigation," Journal of Magnetism and Magnetic Materials, vol. 393, no. 11, pp. 1-7, 2015.

[20] V. G. Kostishyn, A. T. Morchenko, and D. N. Chitanov, "Design of high-coercivity epitaxial magnetic garnet films for thermomagnetic recording and nanotechnology," Journal of Alloys and Compounds, vol. 586, no. 1, pp. S317-S321, 2014.

[21] G. Hrkac, T. G. Woodcock, K. T. Butler et al., "Impact of different Nd-rich crystal-phases on the coercivity of Nd-Fe-B grain ensembles," Scripta Materialia, vol. 70, no. 1, pp. 35-38, 2014.

[22] H. Wang, C. S. Li, T. Zhu, B. Cai, G. Huo, and N. Mohamed, "Effect of ball scribing on magnetic barkhausen noise of grain-oriented electrical steel," Journal of Materials Science and Technology, vol. 29, no. 7, pp. 673-677, 2013. 

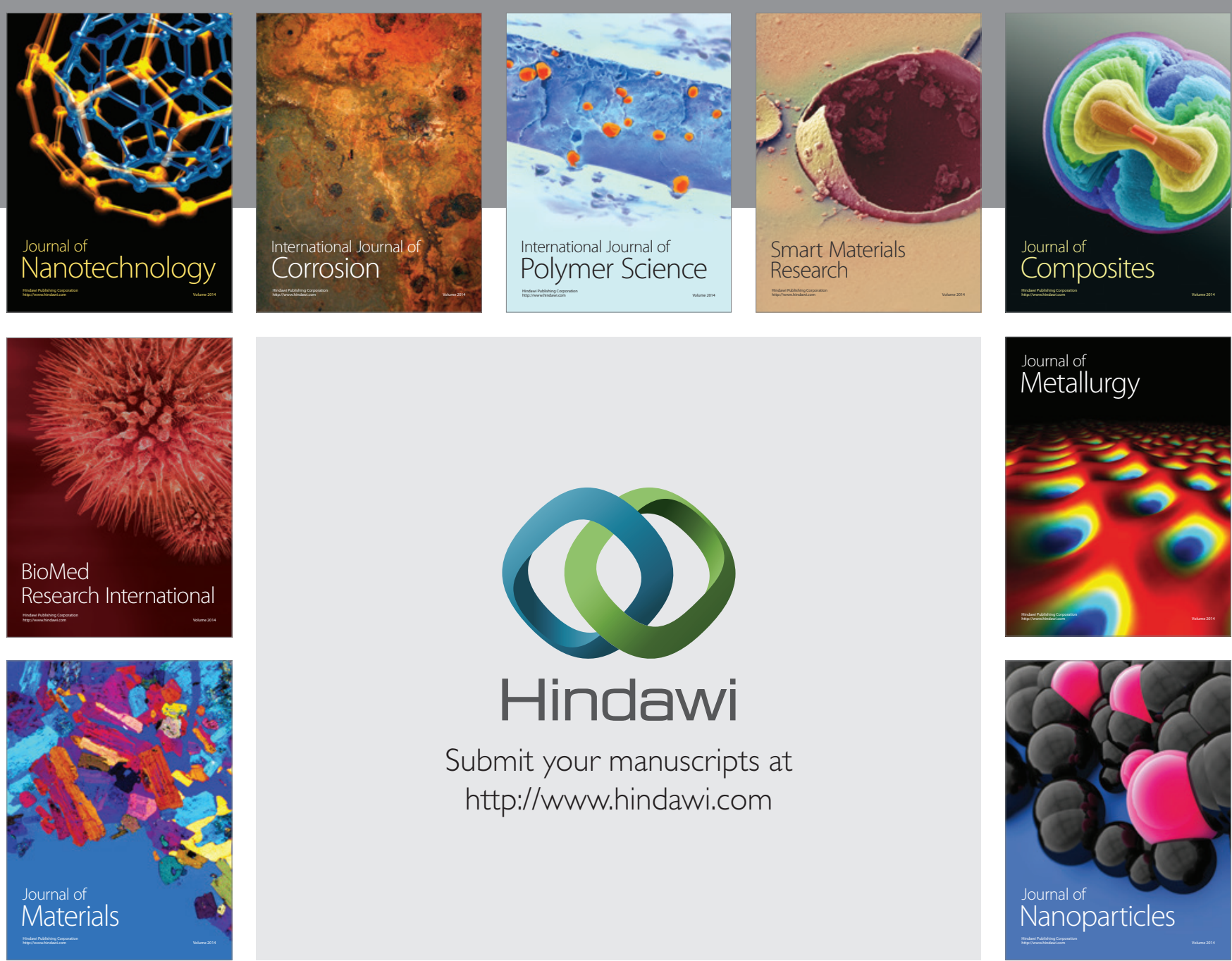

\section{Hindawi}

Submit your manuscripts at

http://www.hindawi.com

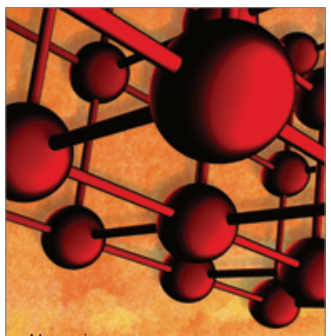

Materials Science and Engineering
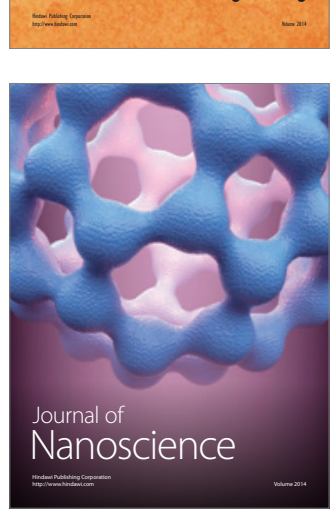
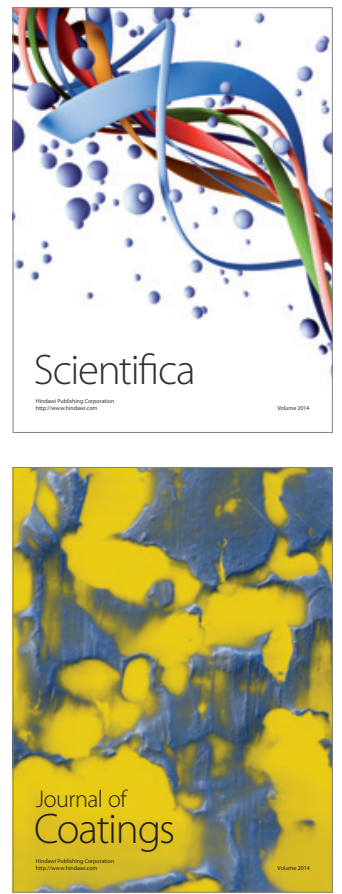
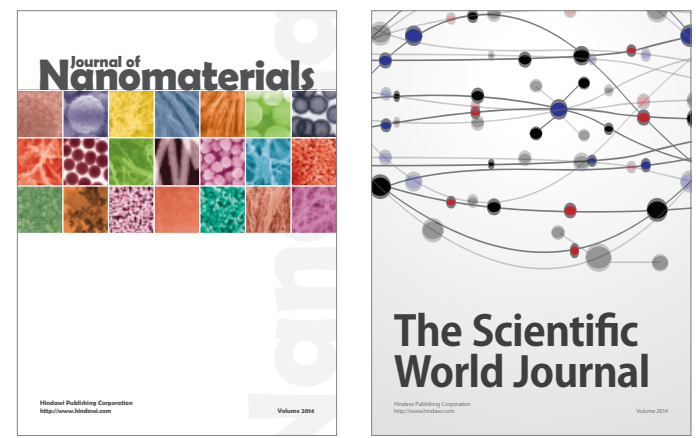

The Scientific World Journal
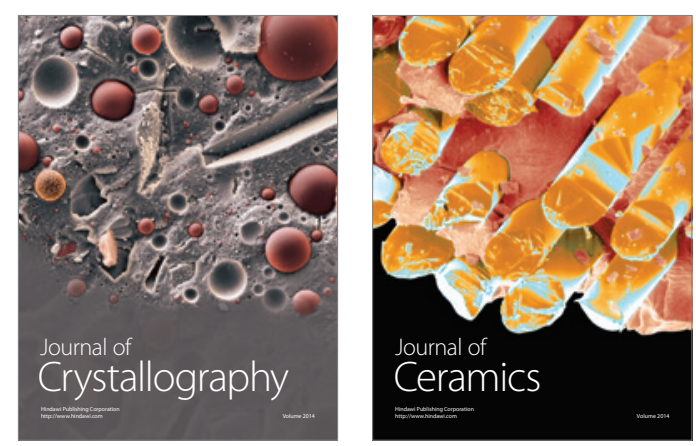
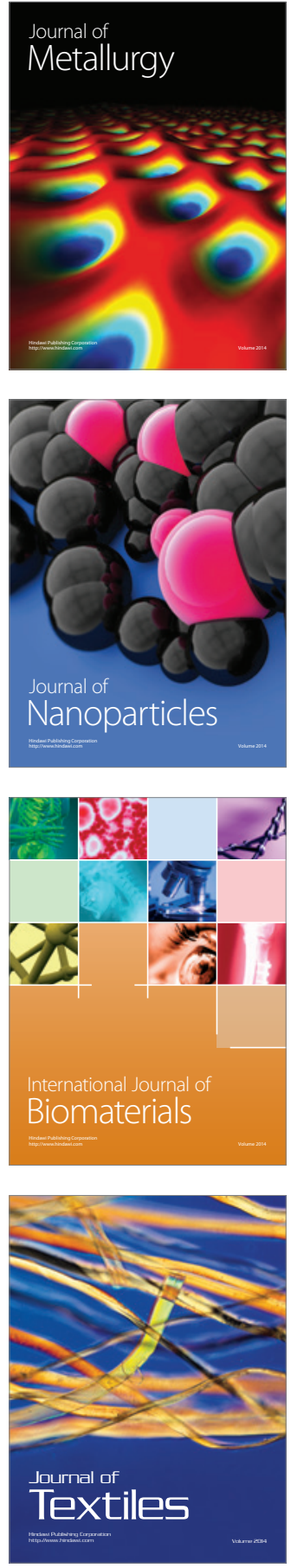